\title{
Digestible Lysine Requirement of Liuzhou Mahua Broilers at Different Growth Stages
}

\author{
Gang Jia, Ying Wang, Qiuhong Deng \& Kangning Wang (Corresponding author) \\ Institute of Animal Nutrition, Sichuan Agricultural University \\ Ya'an 625014, Sichuan, China \\ Tel: 86-835-288-5005Ｅ-mail: jiagang700510@163.com \\ Xiongxian Guo \\ Vocation high school of Hanyuan \\ Hanyuan 625302, Sichuan, China
}

Supported by the specific research supporting program for academic sustentation research team in Sichuan Agricultural University

\begin{abstract}
Experiments were conducted to determine the digestible lysine (DLys) requirement of Liuzhou Mahua broilers from 1 to $21 \mathrm{~d}$ and from 22 to $42 \mathrm{~d}$ of age. Monofactorial design was adopted in this study. 1200 one-day-old healthy broiler chicks were divided randomly and evenly into five treatments, and were all fed with isoenergetic diet (with ME of $3.0 \mathrm{Mcal} / \mathrm{kg}$ ) but with graded levels of DLys: $1.22 \%, 1.12 \%, 1.02 \%, 0.91 \%$ and $0.81 \%$ during the period of 1 to 21 days; $1.13 \%, 1.02 \%, 0.92 \%, 0.82 \%$ and $0.71 \%$ during the period of 22 to 42 days. The results showed that the DLys level in diet had a quadratic relationship both with the average daily gain (ADG) and feed:gain ratio $(\mathrm{F} / \mathrm{G})$. For Liuzhou Mahua broilers from 1 to $21 \mathrm{~d}$ of age, ADG was the highest at the DLys level of $1.12 \%$, which was not significantly different from those at the levels of $1.22 \%$ and $1.02 \%(P>0.05)$, and F/G was the lowest at the DLys level of $1.22 \%$. For Liuzhou Mahua broilers from 22 to $42 \mathrm{~d}$ of age, at the DLys level of $1.02 \%$, ADG was the highest, and F/G was the lowest, but not significantly different from those at the levels of $1.13 \%$ and $0.92 \%(P>0.05)$. According to regression analysis results, for Liuzhou Mahua broilers from 1 to $21 \mathrm{~d}$ of age, the optimum DLys requirement was $1.07 \%$ with ADG as the indicator, and was $1.13 \%$ with F/G as the indicator. For Liuzhou Mahua broilers from 22 to $42 \mathrm{~d}$ of age, with ADG and F/G as the indicator, DLys requirement were $0.89 \%$ and $0.84 \%$, respectively. Liuzhou Mahua broilers were not as sensitive to DLys concentration variation as fast-growing broilers from abroad.
\end{abstract}

Keywords: Liuzhou Mahua broilers, Digestible lysine, Requirement

\section{Introduction}

Liuzhou Mahua broilers are a breed of local chickens originally from Guangxi Province, China, and they have the features of tender meat, high feed conversion and high disease resistance. This study investigated the DLys requirements of Liuzhou Mahua broilers at different growth stages, in order to guide the feed preparation for Liuzhou Mahua broiler and to provide scientific references for the feeding standard of Liuzhou Mahua broilers. Due to the differences in genetics, body compositions and growth rates, different breeds of broiler chickens had different amino acid requirements, and the amino acid requirements resulted from different evaluation indicators were also different (Rostagno and Pack, 1995). In 1986, China issued a tentative feeding standard for local broiler chickens, but in this standard many indicators followed the feeding standards for Guangdong Sanhuang broilers and Taiwan local chickens, which may not be suitable for local chickens from other areas. Liuzhou Mahua broiler chicken is an excellent breed of local chicken, but there is almost no research on its nutritional requirements, let alone researches on its Lys requirement. Therefore, in this study graded DLys concentrations were adopted, and quadratic regression analysis was utilized to determine the DLys requirements of Liuzhou Mahua broilers from 1 to $21 \mathrm{~d}$ and from 22 to $42 \mathrm{~d}$ of age.

\section{Materials and methods}

\subsection{Test chickens}

In this study, monofactorial design was adopted. Based on the principles of male and female in half and minimum body weight difference, 1200 one-day-old Liuzhou Mahua broiler chicks were divided into five 
treatments (the total body weight difference between treatments was less than 2 grams), with 4 replicates per treatment, and 60 chicks in each replicate. Upon finishing the first phase of the experiments (from 1 to $21 \mathrm{~d}$ of age), the second phase (from 22 to $42 \mathrm{~d}$ of age) was conducted on the same set of chicks used in the first phase.

\subsection{Diets}

In this study the energy level of diets was determined according to the research results of energy requirements of other local chickens obtained by other Chinese researchers, as well as the energy requirements in the China Feeding Standard of Chicken issued in 1986. The DLys concentration in the diets was set to five levels: $1.2 \%$, $1.1 \%, 1.0 \%, 0.9 \%$ and $0.8 \%$ for 1 to $21 \mathrm{~d}$ of age, $1.1 \%, 1.0 \%, 0.9 \%, 0.8 \%$ and $0.7 \%$ for 22 to $42 \mathrm{~d}$ of age. The amino acid profile used in this study was the average of ideal amino acid profiles for broiler chickens in NRC (1984), SCA (1987), NRC (1994), IICP and Han \& Baker (1994). The true amino acid digestibility was chosen according to the NRC (1994) recommendation. The amount of mineral premix and vitamin premix added to the diets followed the NRC (1994) recommendation for poultry nutritional requirement. The composition and nutrient levels of the diets for the test chickens at different growth stages were shown in Table 1 and Table 2 . Chickens from 1 to $21 \mathrm{~d}$ of age were fed with powder feed, and chickens from 22 to $42 \mathrm{~d}$ of age were fed with pellet feed.

\subsection{Feeding management}

During the experiments, the feed intake and the health status of the test chickens, and any abnormal circumstances were recorded accurately. The chickens were weighed once a week. To ensure weighing accuracy, feed was removed from the cages in turn, with the time interval of $7 \mathrm{~min}$, and the chickens were deprived of feed for $8.5 \mathrm{~h}$ before being weighed. The chickens were allowed ad libitum to the diets and water, and the chicken coop was kept at normal temperature and relative humidity, and with good ventilation. The room temperature was set as the following: $32 \sim 35^{\circ} \mathrm{C}$ during the first week, $27 \sim 32^{\circ} \mathrm{C}$ during the second week, $22 \sim 29^{\circ} \mathrm{C}$ during the third week, and not lower than $21^{\circ} \mathrm{C}$ after the third week. The chicken coop was disinfected and immunized using conventional methods.

\subsection{Measuring indicators and methods}

$\mathrm{CP}$ (Kjeldahl method) and crude water in the feed ingredients were determined, and $\mathrm{CP}, \mathrm{FE}, \mathrm{CF}, \mathrm{ASH}, \mathrm{Ca}, \mathrm{P}$ and crude water in finished feed were determined.

Average daily feed intake, $\mathrm{ADG}$ and $\mathrm{F} / \mathrm{G}$ were used as indicators of growth performance, in which $\mathrm{F} / \mathrm{G}=$ average daily feed intake / $\mathrm{ADG} \times 100 \%$.

\subsection{Data processing and statistical analysis}

Excel software and SPSS statistical software were used to analyze the data. Tukey test was adopted for multiple comparison, and quadratic regression analysis for the estimation of the optimum DLys requirement.

\section{Results}

\subsection{DLys requirements of Liuzhou Mahua broiler chickens from 1 to 21 d of age}

The results of ADG, daily feed intake and F/G of the test chickens from 1 to $21 \mathrm{~d}$ of age were shown in Table 3 . As shown in Table 3, during the growth period of 1 21 days, ADG of the chickens increased with the increase of the DLys level in diets, but as the DLys level reached the highest level of $1.22 \%$, ADG decreased instead. In all treatments, ADG was the highest when DLys level was at $1.12 \%$, which was significantly higher than those at the DLys levels of $0.91 \%$ and $0.81 \%(P<0.01)$, but not significantly different from those at the levels of $1.22 \%$ and $1.02 \%$. At the DLys level of $0.81 \%$, ADG of $14.21 \mathrm{~g}$ was the lowest, which was significantly lower than those at other levels $(P<0.01)$. The DLys level had no significant effect on the chickens' feed intake. F/G decreased with the increase of the DLys level, and F/G was the best at the DLys level of $1.22 \%$, which was significantly better than those at other DLys levels $(P<0.05$, or $P<0.01)$. F/G was the highest at the DLys level of $0.81 \%$, which was significantly higher than those at other DLys levels $(P<0.01)$. There was no significant difference of $\mathrm{F} / \mathrm{G}$ between the DLys levels of $1.12 \%$ and $1.02 \%$, but they were significantly lower than that at the DLys levels of $0.91 \%$ and $0.81 \%(P<0.01)$.

The DLys requirement was estimated using a quadratic regression equation based on $99 \%$ of the optimum response, which was not significantly different from the best effects. As shown in Table 5, the DLys requirement of Liuzhou Mahua broilers from 1 to $21 \mathrm{~d}$ of age were $1.07 \%$ and $1.13 \%$, respectively, and the converted total Lys requirements in this study were $1.23 \%$ and $1.30 \%$, respectively, based on ADG and F/G. 


\subsection{DLys requirements of Liuzhou Mahua broiler chickens from 22 to $42 \mathrm{~d}$ of age}

The results of ADG and F/G of the chickens from 22 to $42 \mathrm{~d}$ of age were shown in Table 4 . As shown in Table 4, when the DLys level was in the range of $0.71 \% \sim 1.02 \%$, for 22 42-day-old chickens, ADG increased as DLys level increased. However, as the DLys reached the highest level of $1.13 \%$, ADG decreased instead. ADG was the highest at the DLys level of $1.02 \%$, followed by those at $1.13 \%$ and $0.92 \%$, and the differences between the three levels were not significant. ADG was the lowest at the DLys level of $0.71 \%$, and it was significantly lower than those at other levels $(P<0.01)$. The DLys level had no obvious effect on the test chicken's feed intake. $\mathrm{F} / \mathrm{G}$ reached the optimum value at the DLys level of $1.02 \%$, but it was not significantly different from those at $1.13 \%$, $0.92 \%$ and $0.82 \%(P>0.05)$. F/G at the DLys level of $0.71 \%$ was significantly higher $(P<0.05$, or $P<0.01)$ than those at other DLys levels.

The DLys requirement was estimated using a quadratic regression equation based on $99 \%$ of the optimum response, which was not significantly different from the best effects. As shown in Table 5, the DLys requirement of Liuzhou Mahua broilers from 22 to $42 \mathrm{~d}$ of age were $0.89 \%$ and $0.84 \%$, respectively, and the converted total Lys requirements in this study were $1.02 \%$ and $0.97 \%$, respectively, based on ADG and F/G.

\section{Discussion}

\subsection{Lys requirement of Liuzhou Mahua broilers from 1 to 21 d of age}

In this study, the regression analysis results showed that the DLys level had a quadratic relationship with ADG and F/G, which was consistent with the results on broilers reported by Han and Baker (1991, 1994), Knowles and Southern (1998), and Mack et al (1999).

Using ADG as the indicator, Garcia and Batal (2005) found that the DLys requirements of Cobb 500 broilers were $0.98 \%$ and $1.01 \%$, respectively, at $4 \mathrm{~d}$ and $21 \mathrm{~d}$ of age, whereas, using $\mathrm{F} / \mathrm{G}$ as the indicator, DLys requirements were $1.08 \%$ and $1.10 \%$, respectively, at $4 \mathrm{~d}$ and $21 \mathrm{~d}$ of age. Both were lower than the results of this study. Similarly, the DLys requirements of Liuzhou Mahua broilers in this study were higher than those of other breeds of broilers reported by researchers outside China (Muramoto et al, 1997; Knowles and Southern, 1998; Barboza et al, 2000). However, using ADG as the indicator, Conhalato et al (1999) estimated that DLys requirement of male Hubbard broilers was $1.05 \%$, which was very close to the results reported here. Dozier et al (2009) reported that DLys requirement of male Ross x Ross TP16 chickens from 14 28 d of age was between $1.07 \%$ and $1.09 \%$ based on ADG, which was consistent with that of Liuzhou Mahua broilers from 1 to $21 \mathrm{~d}$ of age in this study; DLys requirement of male Ross x Ross TP16 broilers was between $1.10 \%$ and $1.15 \%$ based on F/G, which was lower than that of Liuzhou Mahua broilers; DLys requirement of male Ross x Ross TP16 broilers was $1.10 \%$ based on both $\mathrm{ADG}$ and $\mathrm{F} / \mathrm{G}$, which was close to that of Liuzhou Mahua broilers in this study.

NRC (1994) recommendation for total Lys requirement of broilers from 1 to $21 \mathrm{~d}$ of age was $1.10 \%$, which was lower than that of Liuzhou Mahua broilers from 1 to $21 \mathrm{~d}$ of age for optimum ADG in this study (1.23\%). Based on ideal protein amino acid profile, IICP (1994) recommendation for DLys requirement of broilers from 1 to 21 $\mathrm{d}$ of age for male and female chickens were $1.12 \%$ and $1.02 \%$, respectively, and the average value was close to the DLys requirement (1.07\%) of mixed feeding Liuzhou Mahua broilers from 1 to $21 \mathrm{~d}$ of age based on ADG in this study.

\subsection{Lys requirement of Liuzhou Mahua broilers from 22 to 42 d of age}

During 22 42 d period, according to the regression analysis results, the DLys levels also showed a quadratic relationship with $\mathrm{ADG}$ and $\mathrm{F} / \mathrm{G}$, and the DLys requirement for the highest $\mathrm{ADG}$ was lower than that for the lowest F/G (as shown in Table 5). Conhalato et al (1999) found that for optimum ADG and F/G, the DLys requirements of male Hubbard chickens from 22 to $42 \mathrm{~d}$ of age were $1.02 \%$ and $0.98 \%$, respectively. The research of Schutte et al (1997) showed that the total Lys requirement of Ross broilers from 28 to $42 \mathrm{~d}$ of age for optimum F/G was $1.19 \%$. The above results demonstrated that Lys requirements of both male Hubbard chickens and Ross broilers were significantly higher than that of Liuzhou Mahua broilers. NRC (1994) recommendation for total Lys requirement of broilers from 22 to $42 \mathrm{~d}$ of age was $1.0 \%$, which was close to that of Liuzhou Mahua broilers for optimum ADG in this study (1.02\%). Based on ideal protein amino acid profile, IICP (1994) recommendation for DLys requirement of male broilers from 22 to $42 \mathrm{~d}$ of age was $0.89 \%$, which was the same as that of mixed feeding Liuzhou Mahua broilers for optimum ADG in this study.

The above comparisons demonstrated that the Lys requirement of mixed feeding Liuzhou Mahua broilers from 1 to $21 \mathrm{~d}$ of age in this study was close to that of fast-growing male broilers, such as Ross and Hubbard, as well as IICP (1994) recommendation of broiler chicks, but slightly higher than NRC (1994) recommendation and that of local breeds of broilers in China. The Lys requirement of Liuzhou Mahua broilers from 22 to $42 \mathrm{~d}$ of age was 
close to NRC (1994) and IICP (1994) recommendations, but significantly lower than the reported results of broilers such as Hubbard and Ross.

\subsection{Analysis of Lys requirement differences for different breeds of chickens}

Using ADG as the indicator, the DLys requirement of mixed feeding Liuzhou Mahua broilers from 1 to $21 \mathrm{~d}$ of age was close to that of fast-growing male broilers from outside China, but for broilers from 22 to $42 \mathrm{~d}$ of age the DLys requirement of Liuzhou Mahua broilers was significantly lower.

In this study, for single Liuzhou Mahua broiler from 1 to $21 \mathrm{~d}$ of age, the average weight gain was around $350 \mathrm{~g}$, and the average feed consumed was about 560g. NRC (1994) recommendation for weight gain and feed consumption of broiler chicks from 1 to $21 \mathrm{~d}$ of age were $590 \mathrm{~g}$ and $880 \mathrm{~g}$, respectively. Therefore, both the absolute feed intake and body weight gain of Liuzhou Mahua broilers from 1 to $21 \mathrm{~d}$ of age were significantly lower than those of fast-growing broilers from aboard, which might be determined by their genetic specificity. In addition, the effect of amino acid variation in feed on weight gain for Liuzhou Mahua broilers was not as big as for fast-growing broilers. For example, during the second week growth of Liuzhou Mahua broilers, below the highest DLys requirement (i.e. in the range of linear response for productivity) with every $0.1 \%$ increase of DLys, ADG of Liuzhou Mahua broilers in this study increased 0.56g, whereas, the ADG increase of fast-growing broilers was 2.89g (Edwards et al, 1999). Therefore, with the variation of Lys concentration in diet, the weight gain increase of Liuzhou Mahua broilers was slow, and not as sensitive to Lys concentration as fast-growing broiler chickens.

\section{Conclusions}

(1) When the ME of diet was $3.00 \mathrm{Mcal} / \mathrm{kg}(12.55 \mathrm{MJ} / \mathrm{kg}$, calculated using $88 \% \mathrm{DM})$, the following results were obtained through quadratic regression analysis:

(1) At $99 \%$ of the maximum quadratic curve response, the DLys requirement of Liuzhou Mahua broilers from 1 to $21 \mathrm{~d}$ of age was $1.07 \%$ based on $\mathrm{ADG}$, and $1.12 \%$ based on $\mathrm{F} / \mathrm{G}$.

(2) At $99 \%$ of the maximum quadratic curve response, the DLys requirement of Liuzhou Mahua broilers from 22 to $42 \mathrm{~d}$ of age was $0.89 \%$ based on $\mathrm{ADG}$, and $0.84 \%$ based on $\mathrm{F} / \mathrm{G}$.

(2) In the range of Lys levels adopted in this study, Liuzhou Mahua broilers were not as sensitive to Lys concentration variations as fast-growing broiler chickens from abroad.

\section{References}

Barboza, W. A., Rostagno, H. S., Albino, L. F. T. and Rodrigues, P. B. (2000). Lysine levels for broiler chickens from 1 to 21 and 15 to 40 days of age. Revista Brasileira de Zootecnia, 29:1082-1090.

Conhalato, G. da S., Donzele, J. L., Albino, L. F. T., Oliveira, R. F. M. de, and Fontes, D. de O. (1999). Levels of digestible lysine for male broiler chickens from 22 to 42 days. Revista Brasileira de Zootecnia, 28:98-104.

Dozier, W. A., Corzo, A., Kidd M. T., et al. (2009). Digestible lysine requirements of male and female broilers from fourteen to twenty-eight days of age. Poult. Sci., 88:1676-1682.

Edwards, H. M. III, Fernandez, S. R. \& Baker, D. H. (1999). Maintenance lysine requirement and efficiency of using lysine for accretion of whole-body lysine and protein in young chicks. Poult. Sci., 78: 1412-1417.

Garcia, A. and Batal, A. B. (2005). Changes in the digestible lysine and sulfur amino acid needs of broiler chicks during the first three weeks posthatching. Poult. Sci., 84:1350-1355.

Han, Y and Baker, D. H. (1994). Digestible lysine requirement of male and female broiler chicks during the period three to six weeks posthatching. Poult. Sci., 73:1739-1745.

Han, Y. and Baker, D. H. (1991). Lysine requirement of fast- and slow-growing broiler chicks. Poult. Sci., 70: 2108-2114.

Knowles, T. A and Southern, L. L. (1998). The lysine requirement and ratio of total sulfur amino acids to lysine for chicks fed adequate or inadequate lysine. Poult. Sci., 77:564-569.

Mack, S., Bercovici, D., De Groote, G., Leclercq, B., Lippens, M., Pack, M., Schutte, J. B., and Van Cauwenberghe, S. (1999). Ideal amino acid profile and dietary lysine specification for broiler chickens of 20 to 40 days of age. Brit. Poult. Sci., 40:257-265.

Muramoto, T., Fujimura, S., Kadowaki, M. and Ishibashi, T. (1997). Effects of excess dietary lysine and total sulfur amino acid on carcass yield of native chicken, Hinai-jidori (Rhode Island Red $\times$ Hinai-dori). Animal Science and Technology, 68:459-465. 
NRC. (1994). Nutrient Requirement of Poultry. 9th Ed. National Academy Press. Washington D.C.

Rostagno, H. S and Pack, M. (1995). Growth and breast meat responses of different broiler strains to dietary lysine. Proceedings of the10th European Symposium on Poultry Nutrition, Antalya, Turkey. pp:260-262.

Schutte, J. B. (1997). Defining lysine requirements of broiler chicks. Feed Mix., 5:26-27.

Table 1. Composition and nutrient levels of diets for chickens from 1 to $21 \mathrm{~d}$ of age (\%)

\begin{tabular}{|c|c|c|c|c|c|}
\hline \multirow{2}{*}{ Ingredient } & \multicolumn{5}{|c|}{ DLys level } \\
\hline & $1.2 \%$ & $1.1 \%$ & $1.0 \%$ & $0.9 \%$ & $0.8 \%$ \\
\hline Corn & 47.597 & 53.386 & 59.026 & 64.696 & 70.298 \\
\hline Soybean meal & 40.6 & 35.7 & 30.87 & 26.03 & 21.25 \\
\hline Fish meal & 4 & 4 & 4 & 4 & 4 \\
\hline soy oil : lard oil $(1: 1)$ & 4.4 & 3.52 & 2.72 & 1.91 & 1.1 \\
\hline DL-Methionine $^{1}$ & 0.33 & 0.28 & 0.24 & 0.19 & 0.15 \\
\hline $\mathrm{CaCO}_{3}$ & 0.72 & 0.76 & 0.79 & 0.82 & 0.84 \\
\hline $\mathrm{CaHPO}_{4}$ & 1.143 & 1.144 & 1.144 & 1.144 & 1.152 \\
\hline Vitamin premix $^{2}$ & 0.03 & 0.03 & 0.03 & 0.03 & 0.03 \\
\hline Choline chloride $^{4}$ & 0.13 & 0.13 & 0.13 & 0.13 & 0.13 \\
\hline Salt & 0.2 & 0.2 & 0.2 & 0.2 & 0.2 \\
\hline $\mathrm{NaHCO}_{3}$ & 0.1 & 0.1 & 0.1 & 0.1 & 0.1 \\
\hline Mineral premix ${ }^{3}$ & 0.5 & 0.5 & 0.5 & 0.5 & 0.5 \\
\hline Salinomycin $^{4}$ & 0.05 & 0.05 & 0.05 & 0.05 & 0.05 \\
\hline Total & 100 & 100 & 100 & 100 & 100 \\
\hline \multicolumn{6}{|l|}{ Nutrient levels } \\
\hline $\mathrm{ME}(\mathrm{Mcal} / \mathrm{kg})$ & 3 & 3 & 3 & 3 & 3.01 \\
\hline $\mathrm{CP}$ & 24.08 & 22.42 & 20.78 & 19.11 & 17.46 \\
\hline Lys & 1.37 & 1.26 & 1.15 & 1.04 & 0.92 \\
\hline DLys & 1.2 & 1.1 & 1 & 0.9 & 0.8 \\
\hline DMet & 0.67 & 0.6 & 0.55 & 0.48 & 0.42 \\
\hline DThr & 0.88 & 0.82 & 0.75 & 0.69 & 0.62 \\
\hline DIle & 0.87 & 0.81 & 0.74 & 0.67 & 0.61 \\
\hline DCys & 0.3 & 0.28 & 0.26 & 0.24 & 0.23 \\
\hline DVal & 0.99 & 0.92 & 0.86 & 0.79 & 0.72 \\
\hline $\mathrm{Ca}$ & 1 & 1 & 1 & 1 & 1 \\
\hline AP & 0.45 & 0.45 & 0.45 & 0.45 & 0.45 \\
\hline
\end{tabular}

${ }^{1}$ The purity of synthesized AA and mineral raw materials were calculated by $98 \%$.

${ }^{2}$ Per kilogram of vitamin premix contained: VA 20 million IU; VD3 2.8 million IU; VE 13,000 IU; VK 5 g; $\mathrm{VB}_{1} 2 \mathrm{~g} ; \mathrm{VB}_{2} 15 \mathrm{~g} ; \mathrm{VB}_{6} 6 \mathrm{~g} ; \mathrm{VB}_{12} 30 \mathrm{mg}$; folacin $500 \mathrm{mg}$; nicacid $35 \mathrm{~g}$; calpanate $25 \mathrm{~g}$.

${ }^{3}$ Per kilogram of mineral premix contained: Fe 80.0 ppm, Cu 8.0 ppm, Mn 60.0 ppm, Zn 40.0 ppm, Se 0.15 ppm, I $0.35 \mathrm{ppm}$.

${ }^{4}$ Salinomycin was in the form of salinomycin sodium, with the content of $10 \%$. Choline chloride was in the form of solid, with the content of $50 \%$. 
Table 2. Composition and nutrient levels of diets for chickens from 22 to $42 \mathrm{~d}$ of age (\%)

\begin{tabular}{|c|c|c|c|c|c|}
\hline \multirow{2}{*}{ Ingredient } & \multicolumn{5}{|c|}{ DLys Level } \\
\hline & $1.1 \%$ & $1.0 \%$ & $0.9 \%$ & $0.8 \%$ & $0.7 \%$ \\
\hline Corn & 50.93 & 57.44 & 63.54 & 69.6 & 75.59 \\
\hline Soybean meal & 39.5 & 33.92 & 28.72 & 23.57 & 18.44 \\
\hline Fish meal & 2 & 2 & 2 & 2 & 2 \\
\hline Soy oil : lard oil (1:1) & 4.05 & 3.1 & 2.18 & 1.29 & 0.42 \\
\hline DL-Methionine $^{1}$ & 0 & 0.02 & 0.03 & 0.04 & 0.05 \\
\hline $\mathrm{CaCO}_{3}$ & 0.32 & 0.28 & 0.25 & 0.2 & 0.16 \\
\hline $\mathrm{CaHPO}_{4}$ & 0.78 & 0.82 & 0.86 & 0.88 & 0.92 \\
\hline Vitamin premix $^{2}$ & 1.2 & 1.2 & 1.2 & 1.2 & 1.2 \\
\hline Choline chloride $^{4}$ & 0.04 & 0.04 & 0.04 & 0.04 & 0.04 \\
\hline Salt & 0.13 & 0.13 & 0.13 & 0.13 & 0.13 \\
\hline $\mathrm{NaHCO}_{3}$ & 0.3 & 0.3 & 0.3 & 0.3 & 0.3 \\
\hline Mineral premix ${ }^{3}$ & 0.5 & 0.5 & 0.5 & 0.5 & 0.5 \\
\hline Salinomycin ${ }^{4}$ & 0.05 & 0.05 & 0.05 & 0.05 & 0.05 \\
\hline Total & 100 & 100 & 100 & 100 & 100 \\
\hline \multicolumn{6}{|l|}{ Nutrient levels } \\
\hline $\mathrm{ME}(\mathrm{Mcal} / \mathrm{kg})$ & 3.00 & 3.00 & 3.00 & 3.00 & 3.00 \\
\hline $\mathrm{CP}$ & 22.69 & 20.81 & 19.05 & 17.28 & 15.51 \\
\hline Lys & 1.26 & 1.15 & 1.03 & 0.92 & 0.81 \\
\hline DLys & 1.10 & 1.00 & 0.90 & 0.80 & 0.70 \\
\hline DMet & 0.63 & 0.57 & 0.52 & 0.45 & 0.40 \\
\hline DThr & 0.83 & 0.75 & 0.68 & 0.61 & 0.54 \\
\hline DIle & 0.82 & 0.74 & 0.67 & 0.59 & 0.52 \\
\hline DCys & 0.29 & 0.27 & 0.25 & 0.23 & 0.21 \\
\hline DVal & 0.93 & 0.85 & 0.78 & 0.70 & 0.63 \\
\hline $\mathrm{Ca}$ & 0.95 & 0.95 & 0.96 & 0.95 & 0.95 \\
\hline AP & 0.41 & 0.40 & 0.40 & 0.40 & 0.40 \\
\hline
\end{tabular}

${ }^{1}$ The purity of synthesized AA and mineral were calculated by $98 \%$.

${ }^{2}$ Per kilogram of vitamin premix contained: VA 20 million IU; VD3 2.8 million IU; VE 13,000 IU; $\mathrm{VK}_{3} 5$ g; $\mathrm{VB}_{1} 2 \mathrm{~g} ; \mathrm{VB}_{2} 15 \mathrm{~g} ; \mathrm{VB}_{6} 6 \mathrm{~g} ; \mathrm{VB}_{12} 30 \mathrm{mg}$; folacin $500 \mathrm{mg}$; nicacid $35 \mathrm{~g}$; calpanate $25 \mathrm{~g}$.

${ }^{3}$ Per kilogram of mineral premix contained: Fe 80.0 mg; Cu 8.0 mg; Mn 60.0 mg; Zn 40.0 mg; Se $0.15 \mathrm{mg}$; I $0.35 \mathrm{mg}$.

${ }^{4}$ Salinomycin was in the form of salinomycin sodium, with the content of $10 \%$. Choline chloride was in the form of solid, with the content of $50 \%$. 
Table 3. Effect of the DLys level on the growth performance of 1 21-day-old Liuzhou Mahua broiler chickens

\begin{tabular}{|c|c|c|c|}
\hline DLys level & ADG $(g)$ & Daily feed intake (g) & Average F/G (g:g) \\
\hline $1.22 \%$ & $15.68^{\mathrm{aA}} \pm 0.41$ & $24.81 \pm 0.33$ & $1.54^{\mathrm{aA}} \pm 0.025$ \\
\hline $1.12 \%$ & $15.84^{\mathrm{aAC}_{ \pm}} \pm 0.47$ & $25.80 \pm 0.50$ & $1.59^{\mathrm{bA}} \pm 0.021$ \\
\hline $1.02 \%$ & $15.31^{\mathrm{abAC}_{ \pm 0.22}}$ & $25.31 \pm 0.46$ & $1.61^{\mathrm{bB}} \pm 0.022$ \\
\hline $0.91 \%$ & $14.94^{\mathrm{bBC}_{ \pm}} \pm 0.10$ & $25.20 \pm 0.18$ & $1.65^{\mathrm{B}} \pm 0.0126$ \\
\hline $0.81 \%$ & $14.21^{\mathrm{cB}} \pm 0.15$ & $25.44 \pm 0.21$ & $1.76^{\mathrm{C}_{ \pm}} \pm 0.0096$ \\
\hline
\end{tabular}

In the same row, values with different superscripts in lower-cases were significantly different $(P<0.05)$, and values with different superscripts in upper cases were significantly different $(P<0.01)$.

Table 4. Effect of the DLys level on the growth performance of 22 42-day-old Liuzhou Mahua broiler chickens

\begin{tabular}{cccc}
\hline DLys level & ADG (g) & Daily feed intake (g) & Average F/G (g:g) \\
\hline $1.13 \%$ & $33.18^{\mathrm{abA}} \pm 0.523$ & $72.25 \pm 1.52$ & $2.18^{\mathrm{aA}^{\mathrm{aA}} \pm 0.022}$ \\
$1.02 \%$ & $34.39^{\mathrm{aA}} \pm 0.71$ & $74.31 \pm 1.86$ & $2.16^{\mathrm{aA}_{ \pm}} \pm 0.014$ \\
$0.92 \%$ & $33.23^{\mathrm{abA}} \pm 0.67$ & $73.26 \pm 0.55$ & $2.21^{\mathrm{aAB}} \pm 0.049$ \\
$0.82 \%$ & $32.92^{\mathrm{bA}} \pm 0.38$ & $72.41 \pm 1.28$ & $2.20^{\mathrm{aA}} \pm 0.027$ \\
$0.71 \%$ & $30.99^{\mathrm{B}} \pm 0.60$ & $72.66 \pm 1.60$ & $2.29^{\mathrm{bB}} \pm 0.023$ \\
\hline
\end{tabular}

In the same row, values with different superscripts in lower-cases were significantly different $(P<0.05)$, and values with different superscripts in upper-cases were significantly different $(P<0.01)$.

Table 5. Estimated DLys requirements of Liuzhou Mahua broilers at different growth stages through regression analysis

\begin{tabular}{|c|c|c|c|c|c|}
\hline $\begin{array}{l}\text { Growth } \\
\text { phase }\end{array}$ & Indicator & $\begin{array}{l}\text { DLys level at } \\
\text { maximum } \\
\text { quadratic curve } \\
\text { response }\end{array}$ & $\begin{array}{l}\text { DLys level } \\
\text { at } 99 \% \\
\text { maximum } \\
\text { quadratic } \\
\text { curve } \\
\text { response }\end{array}$ & $\begin{array}{l}\text { Total Lys } \\
\text { requirement }\end{array}$ & Regression equation \\
\hline \multirow{2}{*}{$1 \sim 21 \mathrm{~d}$} & $\mathrm{ADG}$ & $1.18 \%$ & $1.07 \%$ & $1.23 \%$ & $\begin{array}{l}\mathrm{y}=-10.78 \mathrm{x}^{2}+25.61 \mathrm{x}+0.531 \\
\mathrm{R}^{2}=0.975\end{array}$ \\
\hline & $\mathrm{F} / \mathrm{G}$ & $1.28 \%$ & $1.13 \%$ & $1.30 \%$ & $\begin{array}{l}y=0.925 x^{2}-2.362 x+3.055 \\
R^{2}=0.959\end{array}$ \\
\hline \multirow{2}{*}{$22 \sim 42 \mathrm{~d}$} & ADG & $0.98 \%$ & $0.89 \%$ & $1.02 \%$ & $\begin{array}{l}y=-46.04 x^{2}+90.32 x-10.01 \\
R^{2}=0.987\end{array}$ \\
\hline & $\mathrm{F} / \mathrm{G}$ & $1.00 \%$ & $0.84 \%$ & $0.97 \%$ & $\begin{array}{l}y=1.612 x^{2}-3.218 x+3.759 \\
R^{2}=0.993\end{array}$ \\
\hline
\end{tabular}

